Revista de Derecho Político, núm. 30, 1989, pp. 243-251

\title{
LAS ELECCIONES MUNICIPALES FRANCESAS DE 12 Y 19 DE MARZO DE 1989
}

CARMEN FERNÁNDEZ-MIRANDA CAMPOAMOR

UNED

Los resultados electorales municipales siempre inciden en la política general del Estado, pero esta influencia es, quizás, más relevante en Francia debido al régimen de compatibilidad existente entre los cargos políticos estatales y locales, con lo que esos resultados afectan muy directamente al reparto de poder del Estado ${ }^{1}$. Es, pues, interesante partir de la situación política general para analizar y extraer consecuencias razonables de los resultados obtenidos por los distintos partidos políticos en estas elecciones.

En las elecciones legislativas de junio de 1988, el partido socialista no logra la mayoría absoluta den 289 escaños, sino que obtiene $276^{2}$; como consecuencia de esta mayoría minoritaria, Mitterrand nombra Primer Ministro a un socialista de su confianza, Rocard, pero un socialista moderado, capaz de pactar en la Cámara los votos que le faltan para poder gobernar. Es en el actual reparto de poder cuando se cumple de manera más clara el parlamentarismo dualista diseñado por la Constitución ${ }^{3}$; el Primer Ministro necesita la confianza del Presidente de la República, con la que cuenta, y la confianza de la Asamblea, que ha de lograr; su mayoría escasa no le permitirá olvidarse de la Cámara y realizar una política exclusivamente del Presidente. Precisa obtener en la Asamblea un consenso continuado e ineludible y, de acuerdo con los deseos manifestados por el electorado, a través de una apertura hacia posiciones de centro ${ }^{4}$, lejos de los clásicos pactos PS-PC que llevaron al poder a F. Mitterrand en 1981.

1 El caso más relevante en los últimos años fue el de J. Chirac, quien, durante el período 1986-1988, compatibilizo su cargo de Primer Ministro con el de Alcalde de París.

2 Asamblea Nacional: PS: 276; RPR y UDF: 271; PC: 27; FN: 1.

3 Ver mi trabajo "La V República francesa: otra experiencia jurídico-constitucional (marzo 1986-mayo 1988)", RDP, núms. 27-28, UNED, 1988.

4 Esa fue la oferta electoral de Mitterrand. 
Desde esta óptica, es necesario analizar las elecciones municipales de 1989, de las que puede esperarse una confirmación o un rechazo de la política de moderación iniciada por Rocard, con el respaldo del Presidente Mitterrand.

Esta breve nota electoral se va a estructurar de la siguiente forma:
A. Campaña electoral.
B. Primera vuelta del 12 de marzo de 1989.
C. Segunda vuelta del 19 de marzo de 1989.
D. Valoración jurídico-política ${ }^{5}$.

\section{A. Campaña electoral ${ }^{6}$}

La campaña electoral para las elecciones municipales de 1989, se caracterizó por los siguientes rasgos:

1) Temor de los partidos a una fuerte abstención, debida al cansancio del electorado que acude por quinta vez a las urnas en el período de un año ?.

2) Campaña poco politizada, más centrada en problemas locales que en grandes temas de política nacional, pese a que existen en ese momento algunos asuntos candentes, capaces de inclinar la opinión del electorado. En primer lugar, la corrupción en el caso Pechinez, que afectó a personas relacionadas con el Elíseo y Matignon. En segundo lugar, las agitaciones sociales llevadas

5 Datos electorales proporcionados por el Ministerio del Interior y recogidos en $L \theta$ Monde, Le Figaro, El Pals y Diario 16, de los dias 12 a 23 de marzo de 1989.

- Siglas utilizadas para designar las distintas formaciones políticas:

RPR. Asamblea para la República (J. Chirac).

UDF. Unión para la Democracia Francesa (V. Giscard d'Esteing).

PC. Partido Comunista (G. Marchais).

PS. Partido Socialista (F. Mitterrand).

FN. Frente Nacional (J. M. Le Pen).

PE. Partido Ecologista o Verde (A. Waechter).

7 Las dos vueltas de las elecciones presidenciales celebradas en mayo de 1988 y las dos vueltas de las legislativas realizadas en junio del mismo año. 
a cabo por grupos musulmanes radicales, apoyando a Jomeini contra el escritor Rushdie, situación que facilita la defensa de una política de dureza contra los trabajadores extranjeros. En tercer lugar, la pérdida de posiciones del europeísmo, representado por el Presidente Mitterrand, ante la preocupación de un sector del electorado por el Mercado Unico de 1993.

3) La izquierda se propone volver a gobernar los ayuntamientos, superando el fracaso de las municipales de 1982. Se logra el acuerdo electoral de socialistas y comunistas en algunas ciudades, pero dejando muy clara la diferencia de programas y de objetivos en política nacional; es decir, sí al acuerdo si es imprescindible para derrotar la derecha, no a la alianza y al pacto. Pese a ello, en el 40 por 100 de las ciudades de más de $\mathbf{2 0 . 0 0 0}$ habitantes no se logro, compitiendo distintas opciones de izquierda.

4) EI RPR y la UDF logran acuerdos electorales en el 95 por 100 de las ciudades de más de 20.000 habitantes. Su objetivo es desquitarse de la derrota sufrida en las elecciones presidenciales del pasado año, manteniendo el gobierno municipal. Siguen la táctica de no aludir en su campaña a cuestiones de inmigración y seguridad, que, si bien les dio la victoria en 1983, hizo resurgir el Frente Nacional de Le Pen.

5) Se prevén dos duelos espectaculares en dos grandes ciudades. En Marsella, entre dos candidatos socialistas, M. Pezot, apoyado por el aparato del PS, y R. Vigoroux, expulsado de este partido y apoyado, discretamente, por el Presidente Mitterrand. En Lyon, entre dos candidatos de la derecha, el actual alcalde, F. Collomb, de la UDF, apoyado por R. Barre, y M. Noir, del RPR, representante de las nuevas generaciones de este partido.

\section{B. Primera vuelta del 12 de marzo de 1989}

El 80 por 100 de los puestos son elegidos en esta primera vuelta, restando 93.671 cargos. Los resultados indican un ligero avance de la izquierda y un ligero retroceso de la derecha, entrando ambos sectores en un equilibrio de fuerzas que les obliga a necesitar, para la segunda vuelta, los votos de las dos formaciones que se presentan como árbitros ineludibles, el FN y el PE. Los rasgos más sobresalientes de esta primera vuelta son los siguientes: 
1) Resultados comparativos de la 1. vuelta:

PRIMERA VUELTA

\begin{tabular}{|l|c|c|}
\hline & 1983 & 1989 \\
\hline Derecha & $50,89 \%$ & $43,23 \%$ \\
Izquierda & $39,75 \%$ & $41,77 \%$ \\
\hline
\end{tabular}

2) Fuerte abstención del electorado, cifrada en un 30 por 100, que llega a un 40 por 100 en las grandes ciudades (París, Lyon, Marsella y Burdeos), siendo directamente proporcional al número de habitantes; se convierte en la mayor abstención registrada durante la $V$ República, debido al cansancio del electorado, ya aludido, y a la ausencia en la campaña electoral de temas de política general, centrándose aquélla en cuestiones puramente locales.

1988:

- Presidenciales: $18,6 \%$

- Legislativas: $34,2 \%$

Elecciones municipales: $1959: 25,3 \%$ (la más alta). 1983: $21,7 \%$

1989:

Elecciones municipales:

- ciudades pequeñas: $22 \%$

- ciudades medianas: $31 \%$

- grandes ciudades: $36 \%$

TOTAL: $33 \%$ 
3) El Partido Ecologista resurge, con un 4 por 100 de votos, tras el desastre de 1983, producto de unas elecciones municipales muy politizadas; parece comenzar una cierta sensibilidad del electorado francés hacia la calidad de vida. Su líder, A. Waechter, manifiesta su intención de mantener la independencia de su partido, no aliándose con el PS (caso alemán), pretendiendo concurrir a la segunda vuelta, sin retirarse en favor de los socialistas.

4) El Frente Nacional de Le Pen, pese a retroceder en número de votos en relación a los comicios anteriores, se consolida en ciertas zonas del país, logrando en ellas el 10 por 100 necesario para pasar a la segunda vuelta; si en 1983 sólo se implantó en Dreux, en este momento lo hace un poco en todo el Estado.

A diferencia del Partido Ecologista, el FN exige a la derecha una alianza de cara a la segunda convocatoria, de forma que si no acepta, mantiene su voto, con' claro perjuicio para el RPR y la UDF.

\section{Segunda vuelta del 19 de marzo de 1989}

Triunfo municipal del conjunto de la izquierda con un 53 por 100 de votos frente al 45 por 100 de la derecha. La abstención se cifra en un 26 por 100. Se pueden señalar los siguientes rasgos de esta segunda vuelta:

SEGUNDA VUELTA

\begin{tabular}{|l|c|c|}
\hline & 1983 & 1989 \\
\hline Derecha & $53 \%$ & $45 \%$ \\
Izquierda & $46 \%$ & $53 \%$ \\
\hline
\end{tabular}


1) Alcaldias de ciudades de más de 30.000 habitantes (538 ciudades) ${ }^{8}$ :

\begin{tabular}{|l|l|l|}
\hline & 1983 & 1989 \\
\hline PS & 66 & 70 \\
PC & 53 & 48 \\
RPR & 47 & 45 \\
UDF & 41 & 39 \\
FN & - & - \\
PE & - & - \\
\hline
\end{tabular}

2) EI PS es el único partido que aumenta sus alcaldias, ganando importantes ciudades: Estrasburgo (capital europea, con una alcaldesa: Catherine Trautman), Mulhuse, Nantes, Avignon, Quimper, Bezier, Tourconing, Orleans, Lorient, Blois, Aix en Provence, Dunkerque.

3) El mantenimiento de las candidaturas del FN en 45 localidades, ante la falta de pactos, ha perjudicado a la derecha; el RPR pierde dos ciudades, pérdida simbólicamente compensada con los arrolladores triunfos de Chirac en París, nuevamente vencedor en los 20 distritos de la capital, y de Michel Noir en Lyon frente a un candidato de la UDF en cuya lista se presentaba R. Barre. Esta última formación política es la gran derrotada, perdiendo cuatro ciudades importantes.

4) EI PC pierde cinco ciudades, entre ellas, Amiens, feudo comunista durante 18 años y segunda ciudad de este partido en número de habitantes (logra mantener la primera ciudad comunista: Le Havre). Su declive en favor de los socialistas es patente.

- IPSOS. EI Pais, 20-III-1989. Los resultados electorales en estas ciudades son un importante punto de referencia para deducir consecuencias politicas. 
5) El FN pierde votos en total, pero logra una alcaldia en Saint Gilles (10.000 habitantes) y entra en varios ayuntamientos importantes: Estrasburgo, Mulhouse, Perpignan (con 8 concejales), Roubaix y Tourconing ${ }^{9}$.

6) El Partido de los Verdes gana votos en relación a la primera vuelta, resistiendo bien el voto útil. Aunque no logra ninguna alcaldía, si un concejal en Paris, se presenta como una agrupación a tener en cuenta políticamente.

\section{Valoración jurídico-política}

El triunfo socialista, tras 10 meses de gobierno, es algo insólito en la $V$ República, en que lo tradicional fue siempre el voto de castigo del electorado al partido en el poder ${ }^{10}$. Tras el análisis de los resultados, pueden señalarse las siguientes conclusiones:

1. Tanto los resultados favorables al PS como la propia campaña electoral poco politizada, permite deducir la satisfacción del electorado con el actual reparto de poder en Francia; ello supone la ratificación del apoyo a la nueva mayoria representada por el Primer Ministro Rocard, político no bien visto por el aparato oficial del partido, pero capaz de abrir el partido socialista hacia posiciones moderadas, logrando una mayoría más amplia que el tradicional electorado del PS.

Esta victoria en las urnas facilitará al Primer Ministro el necesario pacto en la Asamblea Nacional a fin de lograr los votos que le faltan para la mayoria absoluta; facilitará, en fin, la obtención de la confianza de la Cámara, imprescindible para gobernar en un sistema parlamentario, dentro del actual reparto de poder.

2. $\quad$ El PC entra en un progresivo declive en favor del socialismo. Finaliza el pacto y la «disciplina republicana»; el PS no necesita a los comunistas. El buen político que es Mitterrand ha sabido captar la necesidad de huir, cara a Europa, de los radicalismos anteriores, buscando una aper-

- Le Pen no logró ser concejal por el distrito 20 de París, único que no obtuvo Chirac en la $1 .^{\circ}$ vuelta.

10 En las municipales de 1977 , la izquierda logró el triunfo como consecuencia del descontento respecto a la política llevada a cabo por Giscard d'Estaing; en las municipales de 1983, por el contrario, el triunfo de la derecha supuso un claro voto de castigo a la línea política de la mayoría socialista-comunista dirigida por F. Mitterrand. 
tura hacia posiciones de centro, más eficaz que los tradicionales pactos de la izquierda.

3. EI FN se consolida como factor permanente del panorama político, aglutinando al sector más radical del electorado conservador. Esto supone un importante escollo para la derecha, pues si se alía con los ultras «pierde su alma», como expresó Michel Noir, si no se alia, salva el honor pero pierde las elecciones ${ }^{11}$.

4. La gran sorpresa de estas elecciones ha sido el progresivo ascenso del Partido Ecologista, que se presenta como un posible elemento de renovación de la izquierda radical.

5. La derecha, RPR y UDF, no logra recuperarse de la derrota sufrida en las presidenciales. Sus líderes, Chirac y Giscard lo atribuyen a su división, ya que donde han participado unidos han triunfado; sin embargo, las bases de estos partidos (poco propicias a la unidad, sobre todo por parte de la UDF temerosa de la hegemonía del RPR), ponen el acento en la falta renovación de programas y valores. Lo cierto es la carencia de un líder capaz de lograr un amplio consenso, alternativa de la apertura propiciada por Rocard; el estorbo ultra y el envejecimiento del aparato central de los partidos ha supuesto el retroceso municipal. Sus mejores triunfos los han logrado hombres jóvenes, más pendientes de que sus ciudades compitan en Europa que de seguir las consignas y maniobras de las sedes centrales. La prensa de estos dias se hace eco de cómo la nouvelle vague se ha hecho con el poder municipal, derrotando a la vieja guardia.

6. Para finalizar, parece ilustrativo señalar dos casos tipo, en las ciudades con mayor número de concejales (salvo París, donde J. Chirac sigue siendo el mejor alcalde, con independencia de sus actuaciones partidistas):

a) En Marsella, triunfo importante del candidato R. Vigouroux, excluido del PS y cuya lista está formada por personalidades independientes, frente al candidato oficial del partido, en alianza con el PC, M. Pezet. Es, por tanto, la imagen de apertura señalada, el factor más importante para el éxito.

b) En Lyon es derrotada la lista del alcalde F. Collomb, de la UDF (en la que se presenta R. Barre), frente al candidato del RPR, de marzo de 1989. 
M. Noir, hombre moderado y emprendedor, alejado de la línea dura de Ch. Pasqua y enemigo de cualquier alianza con Le Pen ${ }^{12}$.

El nombre de Michel Noir salta a la política, no sólo como triunfador local sino como serio rival para el líder del RPR, J. Chirac.

12 Es la primera vez, desde 1905, que un candidato derrota a un alcalde. 